\title{
NEW FINANCE: TECHNOLOGY DRIVEN FINANCIAL INNOVATIONS
}

\author{
Pawel Golab, Warsaw University of Technology, Poland \\ Jan Monkiewicz, Warsaw University of Technology, Poland \\ Marek Monkiewicz, Main School of Commerce, Warsaw, Poland
}

dx.doi.org/10.18374/IJBR-21-1.1

\begin{abstract}
Since the beginning of the century, modern financial systems have been experiencing a period of dynamic change. These changes have caused the uniform fabric on which the systems were based for a long time to become eroded and a multitude of alternative solutions to appear in their place. The existing systems are becoming increasingly heterogeneous and increasingly less transparent. In addition to the traditional financial system based on highly regulated financial intermediaries with a legal monopoly, an alternative sector is emerging. It is based on an often different market infrastructure that allows the direct allocation and acquisition of funds on a P2P or B2B basis as well as on other rules and intermediary entities. A special role is played in this process of change by current technological innovations, especially the ubiquitous digitisation of financial systems. This state of affairs creates conceptual and terminological confusion, which hinders the process of academic communication and complicates the comparison of empirical research results and theoretical reflections. The aim of this paper is systematization of various concepts of new finance and analysis of its main components in a wider systemic context.In the analysis which follows special attention is given to the architecture of digitalised financial systems, changing nature of financial services providers and new challenges facing public supervisory systems. The basis of the analysis is a critical review of the literature on the subject, both domestic and foreign.
\end{abstract}

Keywords: alternative finance, digital finance, fintech, suptech, cyberrisk 